\title{
SEWPS
}

SPRU Electronic Working Paper Series

\author{
Paper No. 178
}

\section{The Impact of Academic Patenting on University Research and its Transfer}

\author{
Gustavo Crespi \\ International Development Research Centre, Ottawa, Canada \\ Pablo D'Este \\ INGENIO (CSIC-UPV), Valencia, Spain \\ \& SPRU-University of Sussex, UK \\ Roberto Fontana \\ Department of Economics, University of Pavia \\ \& CESPRI - Bocconi University
}

\section{Aldo Geuna}

Department of Economics S. Cognetti de Martiis University of Torino, Italy

\& SPRU-University of Sussex, UK

December 2008

The Freeman Centre, University of Sussex, Falmer, Brighton BN1 9QE, UK Tel: +44 (0) 1273678175 


\title{
The impact of academic patenting on university research and its transfer
}

\author{
Gustavo Crespi, \\ International Development Research Centre, Ottawa, Canada \\ Pablo D'Este , \\ INGENIO (CSIC-UPV), Valencia, Spain \\ \& SPRU-University of Sussex, $U K$ \\ Roberto Fontana, \\ Department of Economics, University of Pavia \\ \& CESPRI - Bocconi University \\ Aldo Geuna, \\ Department of Economics S. Cognetti de Martiis University of Torino, Italy \\ \& SPRU-University of Sussex, UK
}

December, 2008

\section{Acknowledgments}

The authors are grateful to Oluwatosin Babalola, Silvia Maffioli and Ana Fernansez Zubieta for their skilful help in the creation of the database. Financial support from the European Commission (FP6) Project, NEST-2006-PATH-Cul, CID, Contract n.: FP6 - 043345 is gratefully acknowledged. Aldo Geuna acknowledges the support from the International Centre for Economic Research (ICER), Turin (I) 


\begin{abstract}
:
This paper contributes to the ongoing debate on the impact of academic patenting. On the basis of CV information and two separate surveys, we provide the first empirical evidence for a sample of UK academics in physics, chemistry, computer science and a subset of engineering. The main contribution of this paper is twofold. First, our econometric results suggest that academic patenting is complementary to publishing at least up to a certain level of patenting output after which we found some evidence of a substitution effect. Second, our analysis of the potential impact of patenting on the other channels of knowledge transfers seems to indicate that patenting does not have a negative impact on the other channels of knowledge exchange. We have found some positive correlation between the stock of patents and other channels of knowledge transfer, however, also in this case, we have found that a substitution effect sets in indicating a inverted $U$ shape type of relationships between patenting and other knowledge transfer channels.
\end{abstract}




\section{Introduction}

The last few years have seen the development of a very large body of literature evaluating the relationships between the increased patenting output of university researchers and their publication output. ${ }^{1}$ The evidence put forward mostly in the US (Thursby et al. (2001); Agrawal and Henderson, 2002) but also in the EU (Breschi et al. 2005; Geuna and Nesta, 2006) indicate that at least for the top academics there is not evidence of substitution effect between the two activities. Top researchers succeed to publish a lot and patent a lot; a high patent output does not seem to affect negatively the publication output of the most prolific researchers.

The main issues investigated in this paper are the following. First, we attempt to redress the lack of systematic evidence put forward for the UK with respect to the relationship between publishing and patenting. In order to do this, we have gathered the full career information (from their CV and two separate surveys) for 157 academic researchers in the field of physics and chemistry. All these academic researchers were included in the UK Research Assessment Exercise 2001 and had been involved at least once in a project funded by the Engineering and Physical Sciences Research Council (EPSRC), so they can be considered both teaching and research active staff. Given the major importance of university-invented patents in Europe ${ }^{2}$ (Crespi et al, 2006), we paid particular attention to identify such patents and include them in the total count of patenting output of the 157 researchers ${ }^{3}$. About $20 \%$ of the researchers had some form of patenting experience. Second, we estimate a panel data model to evaluate the effect of past patenting involvement on the publication output of the researcher. In particular we investigate the extent to which the relationship between these two variables is affected by non-linearities and other variables related to researcher's ability and scientific field.

Finally, the literature has only been concerned with the impact that patenting can have on publishing; except for the work of Valentin and Jensen (2007) very little attention has been given to the potential effect that an increased patenting activity can have on the other knowledge transfer channels between university and industry. Circumstantial evidence from top R\&D managers in Denmark, France and the US indicates the existence of frictions between business and more active patenting academics (or TTOs managers enforcing university rights) due to the increasing attempt to appropriate the return of the invention by the university. This friction may have resulted in lower (less successful) interactions between companies and academic researchers (see stagnation of business finance of HERD, OECD sources). We examine how university-industry interactions with industry performed by our sample of researchers can be affected by their historical involvement in patenting. Are those researchers with an important involvement in patenting during their career also successful in other forms of interaction with industry, or is the focus on patenting affecting negatively the other channels of communication between academics and business?

\footnotetext{
${ }^{1}$ See the EINT special issue edited by Geuna and Mowery (2007) for the assessment of current situation in Europe and the US.

${ }^{2}$ These are patents with at least one academic inventor (some of the research was carried out at the university) but the assignee is not the university (usually a company).

${ }^{3}$ In other words, our sample includes academic inventors whose patents are owned by universities and academic inventors whose patents are owned by a third party. Of course we also include in the sample non-patenting researchers.
} 
The main contribution of this paper is twofold. First, although much is know about the complementary effect between patenting and publishing for top scientists, not much is known for the rest of the population (those researchers that are research active but they are not in the top 5/10\% in terms of productivity) and even less is known about the process of human capital accumulation in the research profession. Our results suggest that academic patenting may be complementary to publishing at least up to a certain level of patenting output after which we found some evidence of a substitution effect. We also found some weak evidence of scientific field effect, with the most basic sciences (physics and chemistry) showing some evidence of crowding out effect while transfer sciences or Pasteur quadrant science (computer sciences and engineering) show evidence of crowding in effects. Second, our analysis of the potential impact of patenting on other knowledge transfer channels seems to indicate that patenting does not have a negative impact. On the contrary we have found some positive correlation between the stock of patents and other channels of knowledge transfer up to a maximum number of patents after which a substitution effect sets in.

\section{Academic Patenting: Claims and Evidences}

The increasing awareness given to technology transfer activities by the university community, has been paired with the legislative and organizational changes necessary to generate an enabling environment for an effective commercialization of academic discoveries through patents. Significant legislative changes have taken place in many industrial countries. In the US, for instance, such policy initiatives include the 1980 Bayh-dole act and the 1986 Federal Technology Transfer Act, to facilitate patenting of publicly funded research. UK has also experienced an important number of policy initiatives in this domain. After 1985 UK universities and public funded research institutions were allowed to take advantage of their own patents. Similarly, policy reforms to foster technology transfer activity were developed in other EU countries, for example Germany and Denmark have transferred the right to the property of an invention by a university employee from the scientist to the university.. In fact by the early 2000s, in most European countries, an invention produced at the university within the normal course of employment belongs to the university, unless otherwise stated in a research contract.

In response to these policy initiatives and organizational changes, universities have become much more active in their effort to commercialize scientific discoveries. Technology transfer activities undertaken by universities have been thriving in the UK, as reflected by the increasing number of technology transfer offices set up by universities over the 1990s - from 23 before 1990 to 116 by 2002 (NUBS et al., 2003). Not surprisingly, patenting activities have also been increasing: for example within the past five years invention disclosure increased from 2,159 in 2000 to 3,029 in 2004 (HEFCE, 2006).

However, it is still a matter of open debate whether the rapid increase in academic patenting in the closing quarter of the $20^{\text {th }}$ century has been driven by the growing technological opportunities in the bio-medical sciences (and probably in ICT) and the feasibility of pursuing those opportunities in university laboratories, than by policy reforms directed to stimulate technology transfer activities (Mowery et al 2001a, Geuna and Nesta, 2006). 


\subsection{Consequences of academic patenting}

Essential to the well documented increase in university patenting is the rapid increase in the number of individual academic scientists who are listed as inventors on patents. This increasing enrolment of academic researchers into patenting activities has generated lot of concerns amongst scholars about its implication on the development of future scientific knowledge. The argument is derived from the fundamentally different reward and incentive systems of academic and private sector research, in terms of (1) the relationship between disclosure versus secrecy and (2) the complementarities and crowding out effects between public and private research expenditures (Dasgupta and David, 1987, 1994).

According to this view, practice and norms in private and public realms are different and therefore conflict may arise due to the difference in reward and incentive system between the two sectors. The rationale is that certain kinds of activities must occur in a setting which is apart from the economic sphere of efficiency and profit making (National Academy of Sciences, 1999). Once the border is crossed, it becomes particularly difficult to manage the profit seeking approach that characterizes commercial activities (Dasgupta and David, 1994; Stern, 1995; Nelson, 2004). These critics echoes the fear of earlier scholars on the implication of commercial involvement for academic researchers on the Mertonian norms and values guiding academic science (see, for instance, Merton, 1968; Mitroff, 1974; Mulkay, 1976)

A core issue relating to academic patenting, is the possibility of corporate influence on the contents of academic research (e.g., Kenney, 1986; Krimsky, 2003; Ziman, 2000) Critics feared that the involvement of academic researcher in patenting activity might interfere with their financial interest and the normal pursuit of science and seek to involve in research that would be patentable and relevant to the industry rather than pursue their research with objectivity (Noble, 1977). This ultimately, violates the disinterestedness norm of science which allow scientist to conduct research for the sole purpose of producing knowledge (Merton, 1968). The changes in research agenda are most often related to an alleged shift towards the more applied research end, which is referred to as the skewing problem (Florida and Cohen, 1999).

Besides the skewing problem, another concern connected to academic patenting is the issue of publication of research results and the opportunity for open discussions among colleagues. This is the case for the culture of openness among academic researchers who freely disseminate information amongst themselves through the publications and thus promote continuous investigation for future advances. Companies, on the other hand, have a responsibility for and a need to protect the value of their investments. These differences in the incentive systems of public and private research create challenges with regard to the dissemination of information, and the access to research result (Hane, 1999). This again, is in opposition to the Mertonian's norm of openness of the academic community, which allows scientist to make public their discoveries. For example, some forms of publication might be delayed or suppressed because firms may ask universities to keep information (temporarily) confidential, which may reduce the incentive to publish and foster that to patents.

Finally, many scholars have highlighted the multiple mechanisms for knowledge exchange between university and industry. Patenting (and licensing) is just one channel among many, including: joint research collaborations, contract research, 
consultancy work, or joint supervision of $\mathrm{PhDs}$, among others. (Bonaccorsi and Piccaluga, 1994; Faulkner and Senker, 1994; Cohen et al., 2002; Bercovitz and Feldman, 2006; D'Este and Patel, 2007).

However, little is known about whether such interaction channels are all complementary or conflict with each other. As Agrawal and Henderson (2002) show with respect to firms collaborating with academic researchers, the firms that most frequently collaborate with academics on patented research are different from those that most frequently collaborate on published research. Likewise, it would be important to disentangle, from the perspective of academic researchers, whether those who patent are also likely to embrace other forms of interactions with industry. This is particularly important in the light of the great emphasis that policy makers place on patenting as a crucial indicator to measure knowledge transfer at universities. If patents do not provide a representative picture of how academics work with industry, then policies encouraging universities to patent and license might be misaligned with the multiplex nature of interactions between university and industry, and thus, with a policy truly oriented to encourage knowledge transfer more widely.

\subsection{Emerging evidence on academic patenting}

In recent years, most studies have focused on the understanding of the relationship between academic patenting and publishing. In the US, assessment of academic scientists have found that patenting skews scientists' research agendas toward commercial priorities, causes delay in the publication of research findings, and crowds out effort dedicated to producing public research (Blumenthal et al., 1996; Campbell et al. 2002; Krimsky, 2003). This work suggests tradeoffs between patenting and research publication.

On the other hand, the few studies that have systematically assessed the relationship between patenting and publishing have provided strong evidence that star scientists can also be researchers actively engaged in patenting. For example, Agrawal and Henderson (2002) studied the patenting activities in a 15-year panel of 236 scientists in two MIT departments, confining their sample to faculty members who have either patented or published or done both during the period 1983-1997, they found that increased patenting activity is correlated with increased rates of citation to the faculty member's. Also, the result of Azoulay, Ding and Stuart (2004), on the impact of patenting on the publication activity of university researchers working in areas related to biotechnology shows that patenting has a positive effect on the rates of publication. Similarly, Thursby and Thursby (2003b) provide information relating to the invention disclosure behaviour of faculty members at six research universities during the period 1983-1999; they found disclosure to be positively related to publications and a measure of department quality. Markiewicz and DiMinin (2004) reported a statistically significant positive effect of researchers' patent stocks on their publication counts, from a sample of 166 academic inventors that were matched to an equivalent number of non-patenting scientists. Finally, the survey of Stephan et al. (2004) of a sample of doctorate recipients on the cross-sectional relationship between patenting and publishing found that patenting and publishing are complementary activities.

The literature on European academic patenting has developed immensely in the last few years (Balconi et al, 2004; Azagra Caro et al (2003); Meyer, 2003 for a survey see Geuna and Nesta (2006)). An increasing number of papers have focused on cross- 
section and time series data from European universities while the previous literature was almost exclusively based on US observations. The recent European literature provides some insights into: (1) what are the characteristics of academic inventors and what is the relationship between patenting and publishing (Breschi at al. 2005; Carayol, 2005; Guldbrandsen and Smeby, 2005; Meyer, Van Looy et al. 2005); and (2) what is the impact of university research patenting on the research practices of academic and industry scientists (Valentin and Jensen 2007).

The former group of studies clearly shows that those academic researchers that were involved in patenting were also very active in publishing. Some of the papers present strong evidence of a complementarity effect between the two research outputs, while others find a lack of evidence of any substitution effect. Overall, the evidence indicates that high quality university scientists are also active in patenting; patenting may be preceded by higher than normal scientific productivity or may be followed by a flurry of publications (such as in the Italian case). Life-cycle effects are present. One paper by Franzoni, Vezzulli and Calderini (2007) provide somewhat contrary evidence; while they find complementary effect for scientist in material engineering, the also find a strong negative (substitution effect) for material chemists when they consider only publication in basic science.

With respect to the second group, the paper by Valentin and Jensen (2007) is a stark wake up call for those policy makers who thought that the introduction of Bayh-Dole type regulation in the European context would provide the solution to the supposed lack of contribution of universities to economic development. The paper provides preliminary evidence that since the law changed in January 2000, allowing the university right of ownership of a patent associated with an invention by a university researcher, there has been a steep decrease in the number of Danish academic inventors involved in patents by dedicated biotechnology firms (DBFs). The authors argue that this decreased contribution is due to the fact that the new regulation, which requires some form of rational contracting to manage the property right, has created a disincentive for collaboration in early stage research where identification of shares or rights is more difficult.

The studies reviewed above showed that while the integration of patenting is well documented across universities, less is understood about the implications within universities as well as for individual scientists. Also, very little reliable historical data on patenting by universities researchers are available for European countries. Past research has used aggregate data based on university or faculty level research; only few recent researches have used individual researchers as the unit of analysis collecting some form of historical data. Additionally, the analysis we present in this paper is, to our knowledge, the first one to examine the relationship between patenting and publishing with respect to the experience of the UK.

\section{Academic patenting of a sample of UK scientists}

This paper aims to contribute to the understanding of the impact of academic patenting using historical data on UK scientists collected on the basis of their CVs and two separate surveys. We want to test two specific hypoteses discussed in the literature presented in the previous section. First, we want to assess if the involvement in academic patenting results in a lower/higher scientific output for our sample of researchers during their academic career; in other words, is academic patenting a 
complementary activity to scientific publishing? Are there are non linearity in the relationship? Second, the involvement in academic patenting may result in less/more successful knowledge exchange via the other channels of exchange; is academic patenting reinforcing the other form of knowledge transfer that involve a direct link with the business community?

To answer these questions we need information about research outcomes and patenting activity for a representative sample of academic inventors. With this aim we built a comprehensive database, which includes detailed information of the patenting and publishing activities of a sample of UK academic researchers since the receipt of their PhD. The researchers in this sample are a subset of the EPSRC (Engineering and Physical Sciences Research Council) funded project coordinator (principal investigator) conducted by D'Este and Patel (2005), which was aimed at assessing the factors that determines the variety of university researchers' interactions with industry. The data includes all principal investigators that had been recipients of EPSRC grants from 1995 to 2003 in 10 scientific disciplines.

Analysis in this research is limited to university researchers from Physics, Computer Science, Mechanical, Aeronautical \& Manufacturing Engineering and Chemistry departments. A sample of researchers was extracted from the EPSRC funded project together with their name, age, email addresses, year in which they obtained their $\mathrm{PhD}$ degree, and their university affiliation. This included 807 researchers, from a total of 56 distinct universities.

The distribution of the researchers across the four disciplines is shown in Table 1 .

Table 1: Distribution of the researchers

\begin{tabular}{lc}
\hline Discipline & $\begin{array}{c}\text { Population } \\
\text { Surveyed }\end{array}$ \\
\hline Chemistry & 271 \\
Computer Science & 162 \\
Mechanical, Aero \& Manufacturing Engineering & 179 \\
Physics & 195 \\
Total & $\mathbf{8 0 7}$ \\
\hline
\end{tabular}

Problems of similar names and initials, as well as changes in the researcher's institution affiliation, makes it difficult to obtain reliable information from the ISI Web of Science database and the European Patent Office (EPO) or US patent office (USPTO). Thus, in order to obtain reliable information of the publication and patenting records of the researchers, we decided to collect the researchers' CV and verify/complement this with online information. From a total of 807 researchers, 649 researchers had a valid e-mail address.

We obtained a total of 167 positive responses, which represent a response rate of about $26 \%$. The nature of the reply from the researchers ranged from sending their web address (where the information can be extracted from), to direct attachment of $\mathrm{CVs}$, to written explanations of both their patenting activity and publication patterns. In order to boost our sample size to include star scientists, we collected information about UK fellows of the American Physical Society (APS). We found 19 UK physicists who are members of this organization. An attempt to trace the e-mail 
address for these researchers was made and this resulted into the identification of 17 researchers with e-mail address. Of the 17 mails sent, we received one auto-replay office that a researcher is retired (that means that we have no possibility to contact him) and 4 researchers responded by the deadline. The total distribution of the response rate between the four disciplines is shown in Table 2.

Table 2: Total response rate

\begin{tabular}{lccc}
\hline Discipline & $\begin{array}{c}\text { Population } \\
\text { mailed }\end{array}$ & $\begin{array}{c}\text { Positive } \\
\text { reply }\end{array}$ & $\begin{array}{c}\text { Response } \\
\text { rate }\end{array}$ \\
\hline Chemistry & 212 & 61 & $28,77 \%$ \\
Computer Science & 133 & 25 & $18,80 \%$ \\
Mechanical, Aero \& Manufacturing Engineering & 145 & 16 & $11,03 \%$ \\
Physics & 176 & 69 & $39,20 \%$ \\
Sum & $\mathbf{6 6 6}$ & $\mathbf{1 7 1}$ & $\mathbf{2 5 , 6 8 \%}$ \\
\hline
\end{tabular}

A common problem with the CVs is that they are mostly not updated with their current publications and the references sometimes did not clearly indicate the type of publication or the journal in which it was published. In order to update the CVs and to cross check publications in referred journals, a comparison with data from the ISI web of knowledge was carried out. Also the year of filing, type of patents (university owned or university-invented -with the researcher listed as an inventor but the patent is not owned by the university Geuna and Nesta (2006)) and status (applied, granted, withdrawn, rejected ${ }^{4}$ ) was extracted from the UK patent office, EPO and USPTO data bases, since most of the information provided for patents was basically the patent application number.

In order to minimize the probability of including wrong information while extracting records from the ISI Web of Science database, a systematic cleaning up algorithm was implemented (see Methodological Appendix)

The final dataset is a panel that follows all academic researchers (inventors or not) from 1975 to 2005. After applying some standard data cleaning routines to control for incomplete and/or inconsistent observations, we are left with 3649 inventor-year observations in the dataset. This corresponds to a total sample of 157 academic researchers of which 36 are also inventors (they filed at least one patent between 1975 and 2004) and 121 are academic researchers without patenting activity. The basic descriptive statistics are summarized in Table 3. The average number of publications per year is $2.9 ; 23 \%$ of individuals have applied for a patent at least once. Our representative inventor is only 45 years old and had obtained her Phd degree in the middle of the 1986. 4\% of researchers in the sample are members of any Royal Society but $38 \%$ of them have achieved tenure (professorship). Finally, $75 \%$ of researchers in our sample provide from Chemistry and Physics scientific fields. When we look at the dynamic aspects the most striking result is the increase in patenting (Figure 1): while in the early 1980s less then $0.5 \%$ of out sample was an inventor in a patent in a year, by the early 2000 s $2 \%$ of the scientists were linked to a patent in a

\footnotetext{
${ }^{4}$ A careful cross search in the national and international patent databases (including WIPO extension) has been carried out to be able to ascertain the status of the patent - e.g. a patent can be withdrawn from the UK patent office where it was first applied for to be submitted to the EPO or USPTO.
} 
year; or while in the early 1980s less then $3 \%$ of the researchers showed up in a patent as inventor, by the early 2000 s this figure had grown up to $20 \%{ }^{5}$

Table 3. Descriptive Statistics.

\begin{tabular}{llccccc}
\hline Variable & Definition & Obs & Mean & Std. Dev. & Min & Max \\
\hline Pub $_{i t}$ & Publications Counts py & 157 & 2.90 & 2.82 & 0.07 & 20.40 \\
$\mathrm{P}_{\mathrm{it}}$ & Patent dummy & 157 & 0.23 & 0.42 & 0.00 & 1.00 \\
Gender $_{\mathrm{i}}$ & Dummy if female & 157 & 0.10 & 0.29 & 0.00 & 1.00 \\
Age $_{\mathrm{it}}$ & Age & 157 & 45.59 & 10.54 & 28.00 & 74.00 \\
$\mathrm{PhD}_{\mathrm{i}}$ & Year of PhD graduation & 157 & 1986.89 & 11.00 & 1956 & 2003 \\
Prof $_{\mathrm{i}}$ & If professor at survey time & 157 & 0.38 & 0.49 & 0.00 & 1.00 \\
Star $_{i}$ & Dummy if member of Royal Society & 157 & 0.04 & 0.21 & 0.00 & 1.00 \\
Times Cited $_{\mathrm{i}}$ & Average citations per paper py & 157 & 2.49 & 0.84 & 0.00 & 4.45 \\
RAE $_{\mathrm{i}}$ & Department RAE score (2001) & 157 & 4.92 & 0.94 & 2.00 & 6.00 \\
Dep Size $_{\mathrm{i}}$ & Department Size at survey time (log) & 157 & 3.58 & 0.66 & 2.30 & 5.01 \\
Chemistry $_{\mathrm{i}}$ & Dummy Variable & 157 & 0.36 & 0.48 & 0.00 & 1.00 \\
Physics $_{\mathrm{i}}$ & Dummy Variable & 157 & 0.39 & 0.49 & 0.00 & 1.00 \\
Computer Science $_{\mathrm{i}}$ Dummy Variable & 157 & 0.15 & 0.35 & 0.00 & 1.00 \\
Engineering $_{\mathrm{i}}$ & Dummy Variable & 157 & 0.10 & 0.30 & 0.00 & 1.00 \\
\hline
\end{tabular}

Figure 1. Proportion of patenting academic researchers per year.

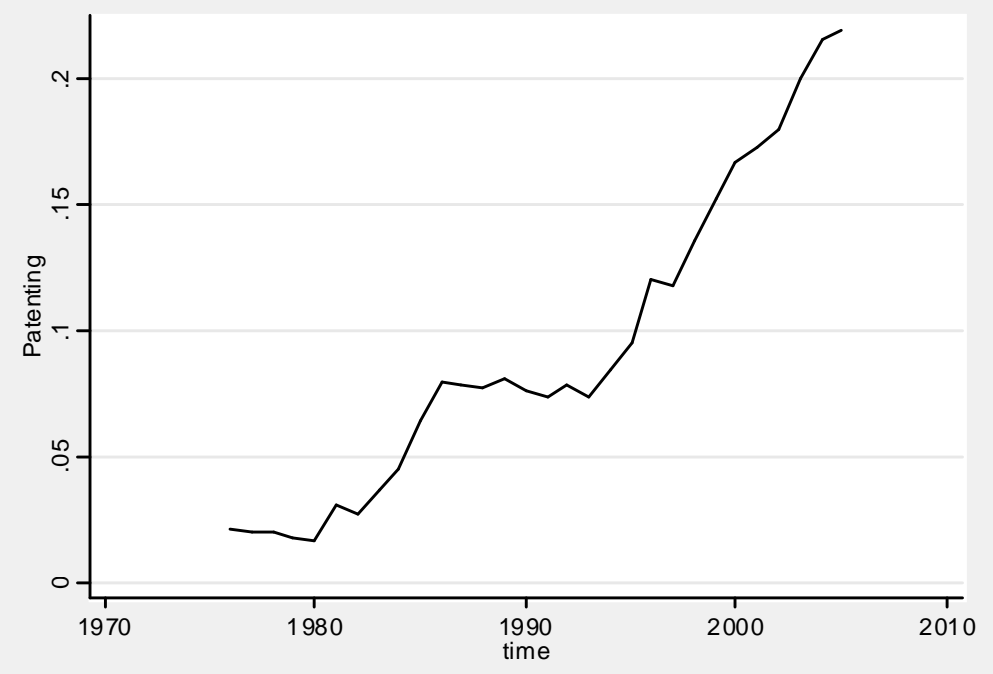

\footnotetext{
${ }^{5}$ This trend could be over-estimated because we are not capturing potential inventors that could have been developing patents in the 80s but then retired and hence they are not in our final the dataset of active researchers in 2001.
} 


\section{The impact of academic patenting on publishing}

To assess the impact of an increased academic patenting on the publication output of UK scientists we follow the methodology developed by Breschi, Lissoni and Montobbio (2005) (thereafter BLM). Using our whole sample of academics we estimated the following model:

$$
\begin{gathered}
Y_{i t}=X_{i t}^{\prime} \beta+\tau P_{i t}+\mu_{i}+\lambda_{t}+\varepsilon_{i t} \\
(\mathrm{i}=1, \ldots \mathrm{N} \text { and } \mathrm{t}=1, \ldots \mathrm{T})
\end{gathered}
$$

where $Y_{i t}$ is a measure of research output, $X_{i t}$ is a set of time varying explanatory variables, $\mu_{i}$ is an individual fixed effect and $\lambda_{t}$ a set of time effects. $P_{i t}$ is a dummy variable that takes value 1 in the years after the first patent (including the year of patenting) and 0 elsewhere. The inclusion of an individual fixed effect would control for those unobserved researcher characteristics that are constant over time and that could be correlated with both patenting activity and research outputs (e.g ability, research productivity, etc).

One particular concern is that some correlation between patenting activity and the error term might remain even after controlling for an individual fixed effect. This could happen if some shocks on publication activity $\left(\varepsilon_{\mathrm{it}}\right)$ could induce researchers to start patenting. In order to purge for this additional source of correlation we also try estimating the model by using instrument variables.

Finally, one remaining issue is about the heterogeneity impact of patenting activity. The model above implicitly assumes that the impact of an increase in patenting is homogenous across inventors with different characteristics including patenting experience and scientific field. In order to explore if this assumption is attainable we also model the impact of patenting as a function of inventors' patenting experience and some other characteristics $\left(\mathrm{Z}_{\mathrm{it}}\right)$. In other words, we estimate:

$$
\begin{gathered}
Y_{i t}=X_{i t}^{\prime} \beta+\tau_{0} P_{i t}+\tau_{1}\left(P_{i t} x Z_{i t}\right)+\mu_{i}+\lambda_{t}+\varepsilon_{i t} \\
(\mathrm{i}=1, \ldots . \mathrm{N} \text { and } \mathrm{t}=1, \ldots \mathrm{T})
\end{gathered}
$$

\subsection{Basic Results}

Table 4 summarises the results for the main regression. Columns (1) to (4) show the results when the model is estimated using a negative binomial regression approach without controlling for unobserved heterogeneity. Column (1) controls only for academic's age and its square and we also control for time and field dummies (not included in the regressions). The results suggest that publications follow a non-linear inverted $U$ shape relationship with age. Publications peak is reached when the researcher is 42 years old. Also we found that although the coefficient for patenting is positive it is not statistically significant. Column (2) shows the results when controlling researcher's unobserved ability by using three observed variables: professorship, average citations and membership to any Royal Society. These dummy variables are all positive, although only the first two are significant. We also 
controlled by gender, which was not significantly different from zero and by year of $\mathrm{PhD}$ graduation, which was significant and negative, suggesting that researchers of more recent cohorts publish less due perhaps to less academic experience. Finally, the quality of researcher's department (as measured by the Research Assessment Exercise score) was positive, while the size of the department was negatively correlated with publications. Indicating that being part of a high quality department increases publication output of the researchers, but, once you have controlled for the quality of the department, its size has a negative impact (indicating a clear lack of economies of scale in knowledge production). After the inclusion of the set of additional control variables, the coefficient of the patenting dummy dropped quite dramatically, however it remained positive but insignificant.

Table 4. Negative Binomial Regressions of Publication Counts

\begin{tabular}{|c|c|c|c|c|c|}
\hline 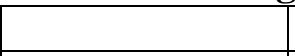 & \multicolumn{2}{|l|}{ 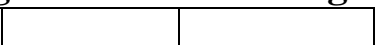 } & & & \multirow[b]{2}{*}{ (5) } \\
\hline COEFFICIENT & (1) & (2) & (3) & (4) & \\
\hline \multirow{2}{*}{$\mathrm{P}_{\mathrm{it}}$} & 0.239 & 0.112 & -0.016 & -0.042 & -0.030 \\
\hline & {$[0.158]$} & {$[0.130]$} & {$[0.058]$} & {$[0.062]$} & [0.698] \\
\hline \multirow{2}{*}{$\mathrm{Age}_{i t}$} & $0.340 * * *$ & $0.256 * * *$ & $0.231 * * *$ & $0.215 * * *$ & $0.194 * * *$ \\
\hline & {$[0.027]$} & {$[0.025]$} & {$[0.016]$} & {$[0.023]$} & {$[0.025]$} \\
\hline \multirow[t]{2}{*}{ Agesqr $_{\text {it }}$} & $-0.004 * * *$ & $-0.003 * * *$ & $-0.003 * * *$ & $-0.003 * * *$ & $-0.003 * * *$ \\
\hline & {$[0.000]$} & {$[0.000]$} & {$[0.000]$} & {$[0.000]$} & {$[0.000]$} \\
\hline \multirow[t]{2}{*}{ Gender $_{i}$} & & 0.178 & 0.196 & 0.538 & 0.574 \\
\hline & & {$[0.203]$} & {$[0.143]$} & {$[0.335]$} & {$[0.352]$} \\
\hline \multirow[t]{2}{*}{$\mathrm{PhD}_{\mathrm{i}}$} & & $-0.063 * * *$ & $-0.071 * * *$ & $-0.101 * * *$ & $-0.105 * * *$ \\
\hline & & {$[0.012]$} & {$[0.012]$} & {$[0.020]$} & {$[0.021]$} \\
\hline \multirow[t]{2}{*}{ Prof $_{i}$} & & $0.440 * * *$ & $0.281 * * *$ & -0.041 & -0.042 \\
\hline & & {$[0.120]$} & {$[0.102]$} & {$[0.179]$} & {$[0.183]$} \\
\hline \multirow[t]{2}{*}{ Star $_{i}$} & & $0.405^{*}$ & $0.418 * *$ & $0.715^{* *}$ & $0.705 * *$ \\
\hline & & [0.233] & {$[0.181]$} & {$[0.315]$} & {$[0.321]$} \\
\hline \multirow[t]{2}{*}{ Times Cited $_{\mathrm{i}}$} & & 0.140 & $0.193 * * *$ & 0.051 & 0.065 \\
\hline & & [0.093] & {$[0.070]$} & {$[0.135]$} & {$[0.137]$} \\
\hline \multirow[t]{2}{*}{$\mathrm{RAE}_{\mathrm{i}}$} & & $0.130^{*}$ & $0.099 * *$ & $0.181 * *$ & $0.188^{* *}$ \\
\hline & & {$[0.067]$} & {$[0.047]$} & {$[0.083]$} & {$[0.084]$} \\
\hline \multirow[t]{2}{*}{ Dep Size $_{i}$} & & $-0.161 *$ & -0.105 & $-0.209^{*}$ & $-0.215^{*}$ \\
\hline & & {$[0.088]$} & {$[0.064]$} & [0.119] & {$[0.121]$} \\
\hline \multirow[t]{2}{*}{ Constant } & $-6.224 * * *$ & $119.061 * * *$ & $135.621 * * *$ & $195.810^{* * *}$ & $204.482 * * *$ \\
\hline & {$[0.496]$} & [23.927] & {$[23.550]$} & [39.895] & [41.183] \\
\hline Observations & 3649 & 3649 & 3649 & 3649 & 3540 \\
\hline Number of idinv & 157 & 157 & 157 & 157 & 157 \\
\hline
\end{tabular}

Time dummies and field dummies included, * significant at $10 \%$, ** significant at 5\%; *** significant at $1 \%$. All the pooled regressions include robust standard errors clustered on individuals in order to allow residuals to be correlated within each individual block. (1) Pooled regression, (2) Pooled regression, (3) Random Effects, (4) Fixed Effects, (5) Fixed Effects instrumental variables. Field and time fixed effects also included.

Column (3) aims at controlling by remaining unobserved heterogeneity by estimating using a random effects binomial model. The coefficient for the patenting activity became negative but insignificant. Results in column (4) control for individual unobserved heterogeneity by using the standard conditional negative binomial model of Hausman, Hall and Griliches (1984) [HHG]. Note that the standard HHG fixed 
effect estimator does not fully control for all stable unobserved covariates. That's because the model is based on a regression decomposition of the overdispersion parameter rather than the usual regression decomposition of the mean, because of this all the time constant variable are not wiped out from the model. Column (4) shows that the result for the patenting dummy drops a lot (which suggests a lack of complementarity between publishing and patenting) but the coefficient is far from being significant. Column (5) controls for any potential endogeneity of the patenting dummy by estimating instrumental variables, we instrument the patenting dummy by using as an instrument the proportion of academic inventors in the same scientific field (Wooldridge, 2002). Following BLM the rationale for this instrument is that researchers that work in an environment where a lot of other researchers are patenting can benefit from this experience becoming easier for them to start patenting. If this rationale is correct, this variable should be correlated with patenting activity but not with publication outputs, making it a valid instrument. Indeed the first stage results suggest that the instrument is strongly correlated with the patenting dummy and the instrument is not significant when included in the main regression. The results indicate that the coefficient for the patenting dummy remains negative, nonsignificant and not statistically different from the previous results suggesting that endogeneity is not an issue in our data. Overall, the results from columns (1) to (5) suggest that patenting activity is not correlated with publications.

Table 5. OLS Linear Regressions of $(\log 1+$ Publication Counts)

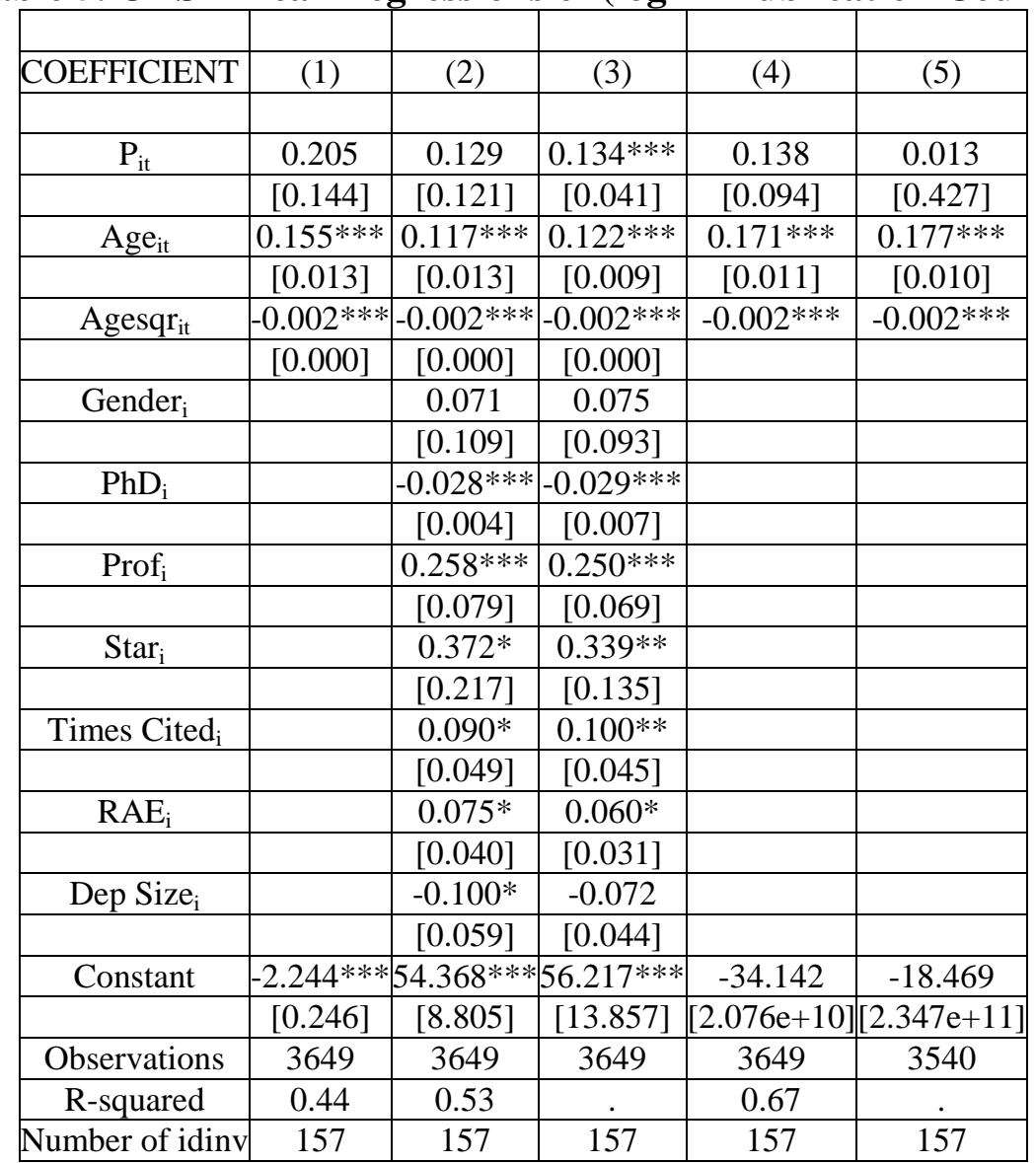

Time dummies and field dummies included, * significant at $10 \%$, ** significant at $5 \%$; *** significant at $1 \%$. All the pooled regressions includes robust standard errors clustered on individuals in order to allow residuals to be correlated within each individual block. (1) Pooled regression, (2) Pooled regression, (3) Random Effects, (4) Fixed Effects, (5) Fixed Effects instrumental variables. Time fixed effects also included. 
In order to test the robustness of our results we change the regression technique and estimate using the standard least squares approach Table 5. Column (1) presents the results when using OLS and controlling only for age, time dummies and field dummies. The result for the patenting is positive and not very far from the figure in the same column of the previous table. In Column (2) we control for researcher characteristics and the coefficient for the patenting dummy drops a lot but it remains non-significant. Column (3) estimates the linear model by random effects, which produces a similar coefficient as in column (2) but the result in now significantly different from zero. Column (4) controls for individual unobserved heterogeneity by including a set of individual fixed effects, we think that this specification is more consistent with the theoretical model because assumes heterogeneity in the mean of the dependent variable. Anyway, column (4) shows that the results for the patenting dummy are not very different from the previous two columns, which suggests that individual observed variables approximate quite well any other omitted characteristic. Finally, Column (5) shows the results of estimating using instrumental variables. The coefficient for the patenting dummy drops quite a lot and it remains insignificant. As for the previous set of regression models, and contrary to most of the results of available literature, we do not find any crowning in effect; it seems that overall academic patenting does not have either a positive or a negative impact on scientific publishing.

Figure 2. Publications vs. Patent stocks

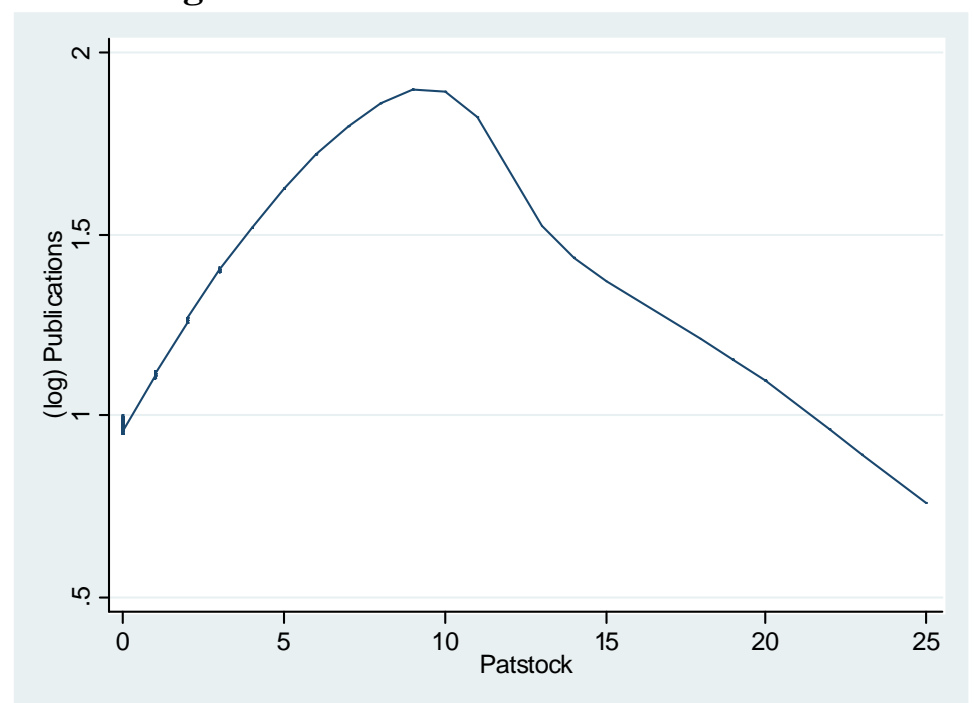

\subsection{Augmented Results}

Previous results suggest that patenting does not particularly harm or help inventor's scientific productivity. However, this finding rests on the particular assumption that the impact of patenting activity can be well approximated by a simple step function. It does not matter how much any inventor is patenting, casual and persistent inventors are treated in the same well. In order to explore whether the effects of patenting depend on the intensity with which patenting activity is carried-out we investigate the shape of the relationship between log publications and the researcher's past stock of patents. Figure 2 plots the shape of the relationship between publications and (past) stock of patents using local linear regression methods. The figure suggests a quadratic 
inverted U relationship between these two variables. This is consistent with previous results Fabrizio and Di Minin (2005) for US scientists. Publication performance first grows until a patent stock of 10 patents is reached. Afterwards this inflexion point, more patenting leads to less publication.

Table 6. Negative Binomial Regressions of Publication Counts (for different definitions of patenting activity)

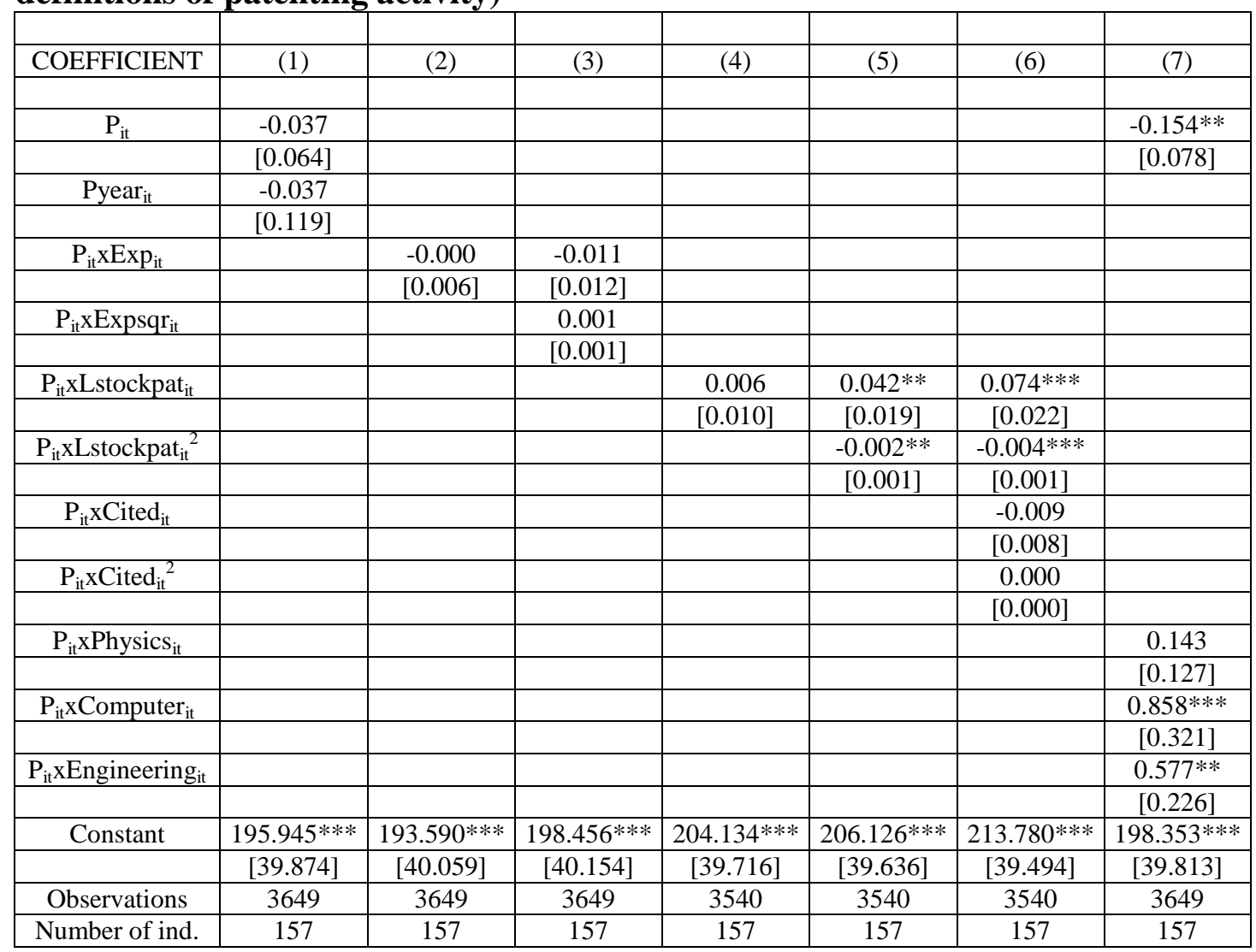

Time dummies and field dummies included, * significant at 10\%, ** significant at 5\%; *** significant at $1 \%$. All columns show negative binomial fixed effects results. All the other control variables are included. Field and time fixed effects also included.

Table 6 explores with more detail if the effects of patenting activity also depends on the intensity on which this activity is carried-out. All the pooled negative binomial regressions in Table 6 include a fixed effect controlling for all unobserved heterogeneity affecting the levels of publication. All the other control variables are included as well as time fixed effects. In column (1) we add as control variable a dummy variable that takes 1 in the year where patenting activity is observed and zero in the rest. By this way we try to capture any other special shock that might occur contemporaneously with the filing of a new patent application but that is transitory. The results suggest that both the patenting regime dummy and the year patenting dummy are not significantly different from zero. Column (2) and (3) replace the patenting dummy activity by patenting experience, measures as the number of years after the first patent. In both cases the results are not significantly different from zero. Columns (4) and (5) replace patenting dummy by the accumulated stock of patents and its square, respectively. The results when including the stock of patents linearly are not significantly different from zero. However, as it is shown in column (5), when 
including a quadratic term for the stock of patents, a strong and significant inverted $U$ pattern emerge. This suggests that an increase of patenting activity intensity first increases the number of publications until a saturation point is reached, after this more patenting actually reduces publication. The inflexion point is reached for about 10 patents.

One remaining concern is about the possibility that unobserved heterogeneity also affects the impacts of patenting. In other words, if more able inventors (the ones whose average paper receive more citations) also patent more, the variable patent stock included in columns (4) and (5) could be capturing the effects of omitted ability or quality rather than the pure incentive effects of patenting. In order to explore this we interact the patenting dummy with the average number of citations per paper. The results are in column (6) where the citations variables are not statistically significant and the results for patent stocks hold. Finally, column (7) interacts patenting dummy with scientific field. We also find an interesting result here: patenting has heterogeneous effects by scientific field. Patenting tends to crowd-out publishing in chemistry and physics (however the value is not significantly different from zero) but it encourages publishing in engineering and computer sciences. These results by field, however, should be taken with caution due to small number of observations in some the fields.

\section{The impact of academic patenting on other channels of knowledge transfer}

In this section we provide a first assessment of the possible impact of academic patenting on other channels of knowledge transfer. As in the case of publishing, one could expect that the engagement in patenting might crowd-out/displace the use of other channels of knowledge transfer to industry. This negative effect may take place as a consequence of potential conflicts of interest on intellectual property rights. The reliance on market-based mechanisms to transfer knowledge may cause a lack of trust in university scientists among industrialist, and affect negatively the other forms of linkages with business partners. Anecdotal evidence from the US and France about the conflict of interests with the business community as a consequence of the very aggressive TTOs approach on IPRs, as well as preliminary evidence of from Denmark (Valentin and Jensen, 2007), support this view.

On the other hand, patenting might be complementary to other forms of knowledge transfer with industry. For instance, university scientists who are involved in patenting might also be particularly inclined to collaborate with business, since patenting might contribute to create awareness for commercial exploitation of their research, as well as a better understanding of the marketplace (Siegel et al., 2003).

In order to examine the relationship between patenting and other channels of interaction, we have estimated the extent to which the amount of patenting per researcher is positively or negatively associated with the frequency in which researchers engage with industry along a variety of interaction channels. The different channels of interaction include: a) joint research agreements with industry; b) contract research agreements; c) consultancy work; d) joint supervision of $\mathrm{PhD}$ students; e) meetings sponsored by industry; and f) setting up equity interests in companies (e.g. spin-offs). 
The data on engagement with industry comes from a survey of academic researchers which asks respondents to report on the number of times they engaged over the period 2002-03 in a number of interaction channels. We surveyed 4337 UK academic researchers within the fields of physical sciences and engineering, and obtained 1528 responses, a 35\% response rate (for details on the survey, see D'Este et al., 2005, and D'Este and Patel, 2007). We re-codified the responses into two categories: 0, if the researcher did not engage in a particular interaction channel over the period 20022003; 1, if the researcher engaged 1 or more times in a particular interaction channel. Accordingly, we have used Logistic regressions to examine the relationship between patenting and the probability of interaction through any of these channels.

With respect to our explanatory variable, we have computed the researcher's total accumulated patents for the period 1978 to 2001 (i.e. 'stock of patents'). This has been done by matching our list of 1528 survey respondents with the information of inventors contained in patents granted by the European Patent Office (EPO). Information on the patents has been collected from the CESPRI-EPO patent database. This databse collects information on all the patents applied for and granted by the European Patent Office (EPO) since its inception in 1978. In particular, we were interested in understanding whether the academics in our EPSRC list were inventors (i.e. they were granted at least one patent since 1978) and, in case they were, how many patents thay had been granted by year between 1978 and 2001. The match between the EPSRC grant recipients and the CESPRI-EPO database was made on the basis of their surname and initials.

To eliminate duplications caused by inventors with the same surname and initials we matched the first two digits of the academic post code as it appears in the EPSRC database with the first two digits of the post code of the inventor as it appears in the CESPRI-EPO database. It has to be noted that this way of deleting duplicates has many shortocomings. For instance, academics may change job over time. Also, academics may commute to work (i.e. they may live and work in places with differrent post codes). This is more likely to occur for universities that are located near the town borders or for big towns with many different post codes (such as London for instance). Doing the cleaning on the basis of this criterion is thus likely to underestimate the number of inventors in our sample of EPSRC survey respondents.

As a robustness check for our matching procedure with the EPO database, we compared the results from our matching with information on patenting records provided directly by 167 university scientist within our sample to whom we recontacted to get information on their patenting records. Our matching with EPO data allows us to correctly estimate $81 \%$ of our 167 sample, in terms of whether these scientists are inventors or not (that is, 133 out of 167 cases). ${ }^{6}$

\footnotetext{
${ }^{6}$ This description, however, must be slightly qualified. While we matched $81 \%$ of the cases correctly, the proportion of mismatches is much higher among inventors than non-inventors. That is, among the 131 scientists who, according to the CVs information are not involved in granted patents, we have a $89 \%$ correct match. So, we correctly identify 117 (out of 131) of those who reported themselves as not involved in patents. However, among those who reported having been involved in granted patents (a total of 33 cases), we are able to capture only $49 \%$ (16 out of 33). We have examined whether our set of mismatched cases have particularly common or distinctive attributes. We observe no significant differences across fields of science (in terms of the proportion of mismatches). That is, there are no differences in the proportion of mismatches between Chemistry, Physics, Computer Science and Mechanical Engineering. Moreover, wee observe no significant differences in terms of university
} 
In short, as a result of the matching process desrcibed above, we have identified 319 inventors from our initial list of 1,528 EPSRC grant recipients who responded to our survey (i.e. $21 \%$ ) - by inventors, meaning researchers who appeared at least once as an inventor in a EPO granted patent over the period 1978-2001. ${ }^{7}$

In order to examine the impact of the past records of patenting on current engagement in other technology transfer activities, we also consider a squared term of the 'stock of patents'. This allows us to investigate whether there are non-linearities in the relationship between the stock of patents and the probability of engagement in a number of interaction channels with business.

Finally, we have considered a set of control variables, both at the individual and the university department level. With regards to the former, we consider: the age of the researcher and the academic status (whether the individual is a professor or not at the time in which the survey was conducted). With regards to the latter, we have included a set of dummies to capture whether the department was highly (i.e. $5^{*}$ scores) or weakly (4 or lower scores) ranked in the Research Assessment Exercise in 2001, the size of the department (measured as the average of full time equivalent staff for the period 1998-2001), and discipline dummy to capture the impact of a researcher being affiliated to any of 9 scientific fields (where Physics is our reference category).

\section{$\underline{5.1 \text { Results }}$}

Table 7 provides the results of the regressions. The table shows that the stock of patents has a positive and significant impact on almost all channels of interaction, with the only exception of 'Industry sponsored meetings'. ${ }^{8}$ However, the results in Table 7 show that there is a threshold number of patents beyond which patenting becomes detrimental to the probability of interaction in 'joint research', 'contract research' and 'consultancy' with business.

Setting up equity interests in companies is the only technology transfer activity for which patents has a positive and significant impact, with no evidence of non-linear effects. Other things equal, an increase in patenting in one unit increases the odds of setting up equity interests in companies by $39 \%$.

Table 7 also shows that age and professorial status have opposite effects on the probability of interaction. In general, older researches are less likely to interact across almost all forms of technology transfer channels. For instance, a 10 years increase in the age of a researcher reduces the odds of interaction in 'joint collaborations' with

affiliation: this was particularly important since one could expect that individuals affiliated to Londonbased universities were more likely to be under-sampled, since, by using postcodes as our matching criteria with EPO, we may have been under-sampling inventors among this group of scientists. The proportion of mismatches between scientists affiliated to London-based vs. non London based universities, was not significantly different. Results of these tests, however, should be interpreted with care due to the small size of the sample.

${ }^{7}$ For 24 individuals the match was not possible, because of lack of information on the surname and initials.

${ }^{8}$ However, if we do not consider the quadratic effect, then the impact of 'stock of patenting' is also positive and significant in this case. 
industry by $16 \% .{ }^{9}$ While being a 'professor' increases the probability of interaction in all channels. For instance, a professor is 2.5 times more likely to engage in 'consultancy' than a researcher with a lower academic status. ${ }^{10}$

With regards to the departmental characteristics, the results on Table 7 show that being affiliated to top-ranked or larger departments has no significant impact on the probability to engage in any of the technology transfer channels examined. However, researchers in low-ranked departments are more likely to engage in 'contract research' and 'consultancy' work.

Finally, Table 7 shows that there are significant differences across disciplinary fields in terms of the probability of engaging in a particular type of knowledge transfer. Researchers in Engineering-related fields are generally more likely to engage in every type of interaction (as compared to researchers in Physics), while researchers in Mathematics are generally less likely to be involved in knowledge transfer activities with business. It is interesting to note that Computer Scientists do not generally differ from their peers in Physics with respect to their interaction with business, with the main exception of engagement in 'spin-off' activities: researches in Computer Sciences are 2.4 times more likely to become academic entrepreneurs compared to researchers in Physics.

\footnotetext{
${ }^{9}$ We have checked with a quadratic effect for age, and significance of the main effect was lost in almost all cases. Only for 'PhD Training' and 'Spin-offs' we observe a result where age has a positive and significant impact and the quadratic effect a negative and significant impact.

${ }^{10}$ We have checked for an interaction effect between age and professor for each of the interaction channels, but results were always not significant.
} 
Table 7. Logistic Regressions: Factors influencing the frequency of interaction, by channel of interaction

\begin{tabular}{|c|c|c|c|c|c|c|}
\hline Variables & $\begin{array}{c}\text { Joint } \\
\text { Research }\end{array}$ & $\begin{array}{l}\text { Contract } \\
\text { Research }\end{array}$ & Consultancy & $\begin{array}{c}\text { Joint } \mathrm{PhD} \\
\text { Training }\end{array}$ & $\begin{array}{c}\text { Industry } \\
\text { sponsored } \\
\text { meetings }\end{array}$ & Spin-offs \\
\hline \multirow[t]{2}{*}{ Stock of Patents } & $0.383 * * *$ & $0.416 * * *$ & $0.389 * * *$ & $0.384 * * *$ & 0.154 & $0.328 * * *$ \\
\hline & $(0.094)$ & $(0.100)$ & $(0.093)$ & $(0.094)$ & (0.099) & $(0.095)$ \\
\hline \multirow[t]{2}{*}{ Stock of Patents ${ }^{2}$} & $-0.025 * * *$ & $-0.026 * * *$ & $-0.025 * * *$ & $0.030 * * *$ & 0.001 & -0.011 \\
\hline & $(0.008)$ & $(0.009)$ & (0.009) & $(0.010)$ & $(0.010)$ & $(0.008)$ \\
\hline \multirow[t]{2}{*}{ Age } & $-0.017 * *$ & -0.011 & $-0.016 * *$ & $-0.019 * *$ & $-0.012 *$ & -0.001 \\
\hline & $(0.007)$ & $(0.007)$ & $(0.008)$ & $(0.007)$ & $(0.007)$ & $(0.010)$ \\
\hline \multirow[t]{2}{*}{ Professorial status } & $0.890 * * *$ & $0.930 * * *$ & $0.921 * * *$ & $0.607 * * *$ & $0.947 * * *$ & $0.745 * * *$ \\
\hline & $(0.146)$ & $(0.150)$ & $(0.151)$ & $(0.149)$ & $(0.148)$ & $(0.211)$ \\
\hline \multirow[t]{2}{*}{ RAE 2001 Low } & 0.154 & $0.261 *$ & $0.375 * *$ & 0.170 & 0.219 & 0.080 \\
\hline & $(0.149)$ & $(0.155)$ & $(0.156)$ & $(0.153)$ & $(0.153)$ & $(0.216)$ \\
\hline \multirow[t]{2}{*}{ RAE $2001 \mathrm{High}$} & -0.031 & -0.028 & -0.045 & -0.125 & -0.193 & -0.008 \\
\hline & $(0.153)$ & $(0.157)$ & $(0.158)$ & $(0.156)$ & $(0.156)$ & $(0.218)$ \\
\hline \multirow[t]{2}{*}{ Staff Dept (log) } & 0.017 & -0.034 & 0.145 & 0.143 & 0.148 & 0.070 \\
\hline & $(0.110)$ & $(0.115)$ & $(0.115)$ & $(0.112)$ & $(0.114)$ & $(0.155)$ \\
\hline \multirow[t]{2}{*}{ Chem. Engineering } & $0.818 * *$ & $1.858 * * *$ & $1.464 * * *$ & $0.978 * * *$ & $1.434 * * *$ & 0.770 \\
\hline & $(0.332)$ & $(0.356)$ & $(0.333)$ & $(0.325)$ & $(0.329)$ & $(0.498)$ \\
\hline \multirow[t]{2}{*}{ Chemistry } & 0.287 & $0.701 * * *$ & $0.564 * *$ & $0.541 * *$ & $0.789 * * *$ & 0.395 \\
\hline & $(0.207)$ & $(0.214)$ & $(0.229)$ & $(0.220)$ & $(0.215)$ & $(0.361)$ \\
\hline \multirow[t]{2}{*}{ Civil Engineering } & $0.543 *$ & $1.305 * * *$ & $1.839 * * *$ & $0.559 *$ & $1.961 * * *$ & $0.992 * *$ \\
\hline & $(0.282)$ & $(0.291)$ & $(0.301)$ & $(0.299)$ & $(0.304)$ & $(0.443)$ \\
\hline \multirow[t]{2}{*}{ Comp. Science } & 0.252 & 0.004 & 0.052 & -0.153 & $0.416 *$ & $0.860 * *$ \\
\hline & $(0.239)$ & $(0.253)$ & $(0.276)$ & $(0.271)$ & $(0.249)$ & $(0.391)$ \\
\hline \multirow[t]{2}{*}{ Electrical \& Electronic } & $0.758 * * *$ & $1.398 * * *$ & $0.853 * * *$ & $0.767 * * *$ & $1.493 * * *$ & $1.127 * * *$ \\
\hline & $(0.228)$ & $(0.238)$ & $(0.246)$ & $(0.237)$ & $(0.238)$ & $(0.360)$ \\
\hline \multirow[t]{2}{*}{ General Engineering } & $0.872 * * *$ & $1.187 * * *$ & $1.569 * * *$ & $0.869 * * *$ & $1.281 * * *$ & $0.988 * *$ \\
\hline & $(0.258)$ & $(0.265)$ & $(0.274)$ & $(0.265)$ & $(0.266)$ & $(0.399)$ \\
\hline \multirow[t]{2}{*}{ Mathematics } & $-1.444 * * *$ & $-0.955 * * *$ & $-0.595 * *$ & $-0.970 * * *$ & $-0.673 * *$ & -0.751 \\
\hline & $(0.282)$ & $(0.275)$ & $(0.294)$ & $(0.301)$ & $(0.267)$ & $(0.519)$ \\
\hline \multirow[t]{2}{*}{ Mechanical, A. \& M. } & $1.003 * * *$ & $1.749 * * *$ & $1.638 * * *$ & $1.056 * * *$ & $1.644 * * *$ & $0.888 * *$ \\
\hline & $(0.229)$ & $(0.243)$ & $(0.246)$ & $(0.235)$ & $(0.240)$ & $(0.367)$ \\
\hline \multirow[t]{2}{*}{ Metallurgy \& Materials } & $0.931 * * *$ & $1.583 * * *$ & $1.640 * * *$ & $0.947 * * *$ & $2.313 * * *$ & 0.751 \\
\hline & $(0.224)$ & $(0.341)$ & $(0.336)$ & $(0.326)$ & $(0.371)$ & $(0.484)$ \\
\hline \multirow[t]{2}{*}{ Intercept } & -0.416 & -0.780 & $-1.793 * * *$ & $-1.254 * *$ & $-1.514 * *$ & $-3.413 * * *$ \\
\hline & $(0.586)$ & $(0.608)$ & $(0.615)$ & $(0.602)$ & $(0.605)$ & $(0.869)$ \\
\hline N. observations & 1447 & 1453 & 1455 & 1455 & 1453 & 1453 \\
\hline Log Likelihood & -879.1 & -841.9 & -829.2 & -846.7 & -858.9 & -497.4 \\
\hline Chi-squared & $229.9 * * *$ & $327.1 * * *$ & $272.1 * * *$ & $165.7 * * *$ & $294.1 * * *$ & $97.6 * * *$ \\
\hline Pseudo R2 (Cox \& Snell) & 0.15 & 0.20 & 0.17 & 0.11 & 0.18 & 0.07 \\
\hline
\end{tabular}

Note: Two tailed t-tests: $* \mathrm{p}<0.10 ; * * \mathrm{p}<0.05 ; * * * \mathrm{p}<0.01$. Standard errors in brackets. 


\section{Conclusions}

In recent years, a large number of studies (using data from the US and other European countries) have tried to assess the impact of increased academic patenting on other knowledge transfer channels focusing especially on publishing. Very little systematic evidence has been gathered till now for UK scientist. This paper provides the first analysis of a sample of UK scientists in the fields of Physics, Chemistry, Computer Sciences and Engineering, based on the information of their CVs (after they have obtained a $\mathrm{PhD}$ ) and two separate survey of their activity in knowledge transfer.

The paper aims to test if a crowding in effect between patenting and publishing (found in other countries) is present in the case of UK. The result of our analysis is less supportive of this interpretation. Our results suggest that academic patenting may be complementary to publishing at least up to a certain level of patenting output after which we found some evidence of a substitution effect. We also found some weak evidence of scientific field effect, with the most basic sciences (physics and chemistry) showing some evidence of crowding out effect while transfer sciences or Pasteur quadrant science (computer sciences and engineering) show evidence of crowding in effects. The robustness of these results have been checked controlling for a large set of characteristics of the scientist and applying econometric techniques to control for heterogeneity and hendogeneity problems.

The paper also presents a study of the possible impact of increased academic patenting on the other channels of knowledge transfer that involve a direct contact with business. The preliminary results of our estimations indicate that patenting seems to be complementary to the other channels of knowledge exchange. We did not find any strong evidence of a substitution effect. However, there is some evidence that points to a decreasing impact (inverted $U$ shape type of relationship), after a certain number of patents the complementarity effect disappears. Further work is needed to test the robustness of these results to the heterogeneity of scientist characteristics and their changes over time. 


\section{References}

Agrawal, A. and R. Henderson (2002): "Putting patents in context: exploring knowledge transfer from MIT", Management Science, 48 (1): 44-60.

Azagra-Caro, J., I. Fernandez de Lucio and A. Gutierrez Gracia (2003): "University patents: output and input indicators ... of what?" Research Evaluation, 12 (1): 5-16.

Balconi, M., S. Breschi and F. Lissoni (2004): "Networks of inventors and the role of academia: an exploration of Italian patent data", Research Policy, 33: 127-145.

Bercovitz, J. and M. Feldman (2003): "Technology transfer and the academic department: who participates and why?", Paper presented at the DRUID Summer Conference 2003, Copenhagen June 12-14, 2003.

Blumenthal, D., E.G. Campbell, M.S. Anderson, N. Causino and K.S. Louis (1996):

"Withholding research results in academic lifescience: evidence from a National survey of faculty", Journal of the American Medical Association, 277 (15): 1224-1228

Breschi, S., F. Lissoni and F. Montobbio (2005): "The scientific productivity of academic inventors: new evidence from Italian data", CESPRI Working Paper 168, 2005.

Cohen, W.M., R.R. Nelson and J.P. Walsh (2002): "Links and impacts: the influence of public research on industrial R\&D”, Management Science, 48 (1): 1-23.

D'Este, P., L. Nesta and P. Patel (2005): "Analysis of University-Industry research collaborations in the UK: preliminary results of a survey of university researchers", SPRU Report, May 2005, http://www.sussex.ac.uk/spru/documents/deste_report.pdf

Dasgupta, P. and P.A.David (1994): "Towards a new economics of science", Research Policy, 23 (5): 487-521.

Fabrizio K. and Di Minin A (2005) Commercializing the laboratory: Faculty Patenting and the Open Science environment Goizueta Business School paper series GBS-2005-004

Franzoni, C., Vezzulli, A, and M Calderini (2007), 'Unequal Benefits of Academic Patenting for Science and Engineering Research' Innovation Studies Working Paper No. 06/2007.

Geuna, A. and L. Nesta (2006): "University patenting and its effects on academic research: the emerging European evidence", Research Policy, 35 (6): 790-807.

Hausmann, J, B. Hall and Z. Griliches (1984), "Econometric Models for Count Data with an application for the Patent-R\&D relationship", Econometrica, 52(4): 909-938.

Krimsky, J. (2003): "Small gifts, conflicts of interest, and the zero-tolerance threshold in medicine", The American Journal of Bioethics, 3 (3): 50-52.

Merton, R.K. (1968), 'The Matthew effect in science', Science, 159: 56-63.

Mitroff, I. (1974), ' Norms and counter-norms in a select group of Apollo moon scientists', American Sociological Review, 39: 579-95.

Mulkay, M. (1976), 'The mediating role of the scientific elite. Social Studies of Science, 6: 445-470.

Mowery, D.C., R.R. Nelson, B.N. Sampat and A.A.Ziedonis (2001): "The growth of patenting and licensing by US universities: an assessment of the effects of the Bayh-Dole Act of 1980", Research Policy, 30 (1): 99-119.

NUBS (2003). UK University commercialisation survey: financial year 2002. AURIL-Nottingham University Business School (NUBS)-UNICO 
Thursby, J.G. and M.C. Thursby (2002): "Who is selling the ivory tower? Sources of growth in university licensing", Management Science, 48 (1): 90-104.

Thursby, J.G., R. Jensen, M.C. Thursby (2001): "Objectives, characteristics and outcomes of university licensing: a survey of major US universities", Journal of Technology Transfer, 26: 59-72.

Valentin, F and RL Jensen (2007), Effects on academia-industry collaboration of extending university property rights Journal of Technology Transfer, 32: 251276.

Wooldridge, J (2002), Econometric Analysis of Cross Section and Panel Data, MIT Press 


\section{Methodological appendix}

\section{$\underline{\text { ISI Web of Science database algorithm }}$}

1. Researchers surnames with his/her first initial only were entered in the general search section; this returns all authors with such name and first initials present in the database. This was then exported to the endnote library.

2. The same procedure in 1 is taken but this time with the first and second initial and the result was exported to a different file in the endnote library. This double searching procedure ensures that the all the researchers' publications are extracted from the web with minimal possibility of including wrong authors. For example a researchers with the name Archer AP could be listed on a publication as either Archer A or Archer AP so a search with Archer A* is unnecessary as this will return researchers surname with many other combination of different initials like Archer AB, AD etc

3. The third search was taken by repeating steps 1 and 2 above but this time including the authors institution address taking notes of changes in address over time, this gives a lower probability of including wrong publications in the resulting data. All the results from this search are thus exported to the same file.

4. Data set resulting from (3) above was cross check with the CV publication lists of the researcher, and wrong publications are eliminated from the file. In most cases though, this list fully represents the researcher's publication lists.

5. The resulting data from (4) above are then compared with data from 1 and 2 following the same elimination method used in 4 .

Data are eliminated on a line-by-line basis taking into consideration, the researchers' co-authors, institution affiliation at a particular point in time, and the name of journal. 